\title{
The puzzle of kidney dysfunction in heart failure: an introduction
}

\author{
Marco Metra $\cdot$ Adriaan A. Voors
}

Published online: 26 February 2012

(C) Springer Science+Business Media, LLC 2012

\begin{abstract}
Heart failure and kidney disease often coexist, and each of the two conditions may lead to progression of the other. Kidney dysfunction is an independent prognostic factor in patients with either acute or chronic heart failure. Worsening renal function may be related with poorer outcomes as well. Multiple mechanisms are involved in the cardio-renal interaction, including hemodynamic abnormalities, neurohormonal and inflammatory activation, oxidative stress, anemia, and abnormalities in mineral and vitamin D metabolism. Serum creatinine has limitations for the assessment of kidney function in patients with heart failure as its short-term changes are dependent on hemodynamic changes and fluid status. New biomarkers of glomerular and tubular function might allow an earlier and more accurate detection of worsening renal function.
\end{abstract}

Keywords Heart failure - Kidney disease - Cardiorenal syndrome

Heart failure (HF) and kidney disease are two of the most important conditions affecting morbidity and mortality of adult subjects. Their prevalence is still growing because of aging of the general population and better treatment of acute conditions. Hypertension, diabetes, and atherosclerosis are coexisting risk factors both for HF and chronic kidney disease (CKD). In addition, there is evidence that

M. Metra ( $\square)$

Institute of Cardiology, University of Brescia, Brescia, Italy

e-mail: metramarco@libero.it

A. A. Voors

Department of Cardiology, University Medical Center

Groningen, University of Groningen, Groningen,

The Netherlands
HF or CKD may affect each other, leading to further progression of the disease.

An impairment of kidney function is present in 30-60\% of the patients with HF and is an independent prognostic factor. Worsening of renal function (WRF) may also be related with poorer outcomes in these patients. Hemodynamic abnormalities such as venous congestion and a low cardiac output, neurohormonal and inflammatory activation, atherosclerosis, and diuretic treatment may all contribute to WRF in the patients with HF. Impaired kidney function is, on its turn, associated with abnormalities in the mineral metabolism, anemia, formation of advanced glycation end-products, further inflammatory and neurohormonal activation, reduced use of life saving therapies, such as inhibitors of the renin-angiotensin-aldosterone system (RAAS), which may all contribute to the increased rate and length of the hospitalizations and increased mortality of patients with HF.

Research has focused on the development of agents that improve kidney function and/or protect from its further impairment in patients with HF. However, so far no agent has been associated with long-term improvement in kidney function and outcomes in patients with HF. These results may be related to either the lack of a pathogenic role of kidney dysfunction in HF, insufficient efficacy of drugs tested and/or lack of accurate and sensitive markers of kidney function. Novel biomarkers, which may better measure changes in renal function, are promising and might contribute to a further understanding of the pathogenic role of kidney dysfunction in HF.

In this special issue of Heart Failure Reviews, experts in the field were invited to submit reviews on the definition, prevalence, prognostic role, and pathophysiological mechanisms of kidney dysfunction in heart failure, as well as the effects of treatment and the role of traditional and 
novel biomarkers. The first articles outline the definition, epidemiology, and clinical impact of CKD and WRF in the patients with HF. Ronco has summarized the main aspects of the definition and classification of the cardio-renal syndromes. He distinguished between the acute or chronic clinical setting with the primary mechanism in either the heart, the kidney, or both. Partially different pathophysiological mechanisms are involved in each of these subtypes [1]. The epidemiology, pathophysiology, and clinical characteristics of kidney dysfunction in acute or chronic $\mathrm{HF}$, respectively, are thoroughly discussed in articles by Carubelli et al. and Dobre et al. [2,3].

The mechanisms leading to kidney dysfunction in the patients with HF have been thoroughly assessed in many recent studies. Neurohormonal activation with increased renal sympathetic stimulation and activation of the RAAS plays a major role causing renal vasoconstriction, and, probably more important, inflammation, oxidative stress, and fibrosis in the kidney. These are the basis for the longterm beneficial effects on kidney function, which have been associated with the administration of RAAS antagonists [4]. However, the beneficial effects of these agents may be counteracted by the secondary increase in prorenin and renin that may activate several alternative pathways, including the recently discovered pro-renin receptor. The role of these systems is thoroughly discussed by Schroten et al. [5].

In addition to the RAAS, inflammatory activation, release of advanced glycation end-products, and atherosclerotic disease of the abdominal aorta have a major role [6-8]. Lastly, research has focused on the role of the hemodynamic abnormalities of HF. Low cardiac output and renal hypoperfusion are major determinants in patients with chronic HF. However, venous congestion and increased renal vein pressure and increased intra-abdominal pressure have a major role in patients with acutely decompensated HF. Reduced glomerular filtration pressure and interstitial edema with tubular damage in the kidney are among the main mechanisms leading to kidney dysfunction $[9,10]$. Other mechanisms, such as abnormalities of vitamin D metabolism and anemia, play a major role $[11,12]$.

The multitude of mechanisms and the pathogenesis of kidney dysfunction point out the inadequacy of its current assessment, simply based on serum creatinine measurements. Serum creatinine has a slow kinetic rising relatively late after acute kidney injury. It is also not sensitive to tubular damage, an event occurring early after kidney injury. It is dependent on dietary intake and muscle mass and, more important for the patients with HF, on volume status and renal perfusion. Thus, a large amount of recent research has been focused on new biomarkers of kidney function [13]. New biomarkers such as cystatin-C may better assess glomerular function and, particularly, may detect its impairment at an early stage and with a greater sensitivity, compared with serum creatinine [14]. Other markers are related with tubular damage and may allow for an earlier detection of acute kidney injury and a better prediction of events, mortality, rehospitalization, and/or WRF in patients with acute HF [13].

Despite recent improvements in our knowledge about the disease, no major progress has been achieved in respect of prevention and treatment of kidney dysfunction in the patients with HF. The different agents and tools that have been proposed and the possible reasons for the recent results are also thoroughly discussed in this special issue $[2,15-17]$. We have been fortunate to receive the contribution by leading experts in each of these topics. Organizing this issue has been fascinating and stimulating. It has been a nice and rewarding experience, and we are convinced this will be the case for our readers, too.

\section{References}

1. Ronco C, Ronco F (2011) Cardio-renal syndromes: a systematic approach for consensus definition and classification. Heart Fail Rev. 1 Jan 2011 [Epub ahead of print] PubMed PMID: 21197571

2. Carubelli V, Metra M, Lombardi C, Bettari L, Bugatti S, Lazzarini V, Dei Cas L (2011) Renal dysfunction in acute heart failure: epidemiology, mechanisms and assessment. Heart Fail Rev. 12 Jul 2011 [Epub ahead of print] PubMed PMID:21748453

3. Dobre D, Rossignol P, Metra M, Zannad F (2011) Can we prevent or treat renal dysfunction in chronic heart failure? Heart Fail Rev. 22 Jun 2011 [Epub ahead of print] PubMed PMID: 21695548

4. Ruggenenti P, Remuzzi G (2011) Worsening kidney function in decompensated heart failure: treat the heart, don't mind the kidney. Eur Heart J 32(20):2476-2478

5. Schroten NF, Gaillard CA, van Veldhuisen DJ, Szymanski MK, Hillege HL, de Boer RA (2011) New roles for renin and prorenin in heart failure and cardiorenal crosstalk. Heart Fail Rev. 22 Jun 2011 [Epub ahead of print] PubMed PMID: 21695549

6. Colombo PC, Ganda A, Lin J, Onat D, Harxhi A, Iyasere JE, Uriel N, Cotter G (2011) Inflammatory activation: cardiac, renal, and cardio-renal interactions in patients with the cardiorenal syndrome. Heart Fail Rev. 19 Jun 2011 [Epub ahead of print] PubMed PMID: 21688186

7. Willemsen S, Hartog JW, Heiner-Fokkema MR, van Veldhuisen DJ, Voors AA (2011) Advanced glycation end-products, a pathophysiological pathway in the cardiorenal syndrome. Heart Fail Rev. 23 Jan 2011 [Epub ahead of print] PubMed PMID: 21259070

8. Bourantas CV, Loh HP, Sherwi N, Tweddel AC, de Silva R, Lukaschuk EI, Nicholson A, Rigby AS, Thackray SD, Ettles DF, Nikitin NP, Clark AL, Cleland JG (2011) Atherosclerotic disease of the abdominal aorta and its branches: prognostic implications in patients with heart failure. Heart Fail Rev. 15 Oct 2011 [Epub ahead of print] PubMed PMID: 22002211

9. Braam B, Cupples WA, Joles JA, Gaillard C (2011) Systemic arterial and venous determinants of renal hemodynamics in congestive heart failure. Heart Fail Rev. 8 May 2011 [Epub ahead of print] PubMed PMID: 21553212

10. Sinkeler SJ, Damman K, van Veldhuisen DJ, Hillege H, Navis G (2011) A re-appraisal of volume status and renal function 
impairment in chronic heart failure: combined effects of pre-renal failure and venous congestion on renal function. Heart Fail Rev. 2 Mar 2011 [Epub ahead of print] PubMed PMID: 21365244

11. Ronco C, Cozzolino M (2011) Mineral metabolism abnormalities and vitamin D receptor activation in cardiorenal syndromes. Heart Fail Rev. 13 Feb 2011 [Epub ahead of print] PubMed PMID: 21327712

12. von Haehling S, Anker MS, Jankowska EA, Ponikowski P, Anker SD (2011) Anemia inchronic heart failure: Can we treat? What to treat? Heart Fail Rev. 7 Oct 2011 [Epub ahead of print] PubMed PMID: 21979835

13. Damman K, Voors AA, Navis G, van Veldhuisen DJ, Hillege HL (2011) Current and novel renal biomarkers in heart failure. Heart Fail Rev. 22 May 2011 [Epub ahead of print] PubMed PMID: 21604178
14. Lassus J, Harjola VP (2011) Cystatin C: a step forward in assessing kidney function and cardiovascular risk. Heart Fail Rev. 23 Mar 2011 [Epub ahead of print] PubMed PMID: 21431356

15. Lazzarini V, Bettari L, Bugatti S, Carubelli V, Lombardi C, Metra M, Dei Cas L (2011) Can we prevent or treat renal dysfunction in acute heart failure? Heart Fail Rev. 10 May 2011 [Epub ahead of print] PubMed PMID: 21556945

16. Felker GM (2011) Loop diuretics in heart failure. Heart Fail Rev. 23 Apr 2011 [Epub ahead of print] PubMed PMID: 21516306

17. Costanzo MR, Jessup M (2011) Treatment of congestion in heart failure with diuretics and extracorporeal therapies: effects on symptoms, renal function, and prognosis. Heart Fail Rev. 11 May 2011 [Epub ahead of print] PubMed PMID: 21559880 